\title{
Depredación oportunista sobre Turdus grayi (Passeriformes: Turdidae) por Dasyprocta punctata (Rodentia: Dasyproctidae) en San Vito, Costa Rica
}

\author{
Diego Ramírez Calvo \\ Ángelo Rivera Vargas \\ Hillary Villalobos Molina \\ Mariana Marín Solano \\ Laura Valverde Cordero \\ Turismo Ecológico, Recinto de Paraíso, Universidad de Costa Rica Sede Atlántico, Cartago, Costa Rica. \\ Víctor J. Acosta Chaves \\ Turismo Ecológico, Recinto de Paraíso, Universidad de Costa Rica Sede Atlántico, Cartago, Costa Rica. \\ victor.acosta@ucr.ac.cr \\ Gestión Ecoturística, Universidad Técnica Nacional Sede Pacífico, Puntarenas, Costa Rica. vracostac@utn.ac.cr
}

La Guatusa, Neque o Agouti Centroamericano (Dasyprocta punctata) es un roedor mediano que se distribuye desde el sur de México pasando por América Central hasta el sur de Bolivia y norte de Argentina (Reid 2009). En Costa Rica esta especie ocurre en casi todo el país hasta una elevación de 2400 msnm (Wainwright 2007, Reid 2009). Sus hábitos de forrajeo son diurnos y crepusculares, siendo un importante dispersor de semillas y frutos, especialmente de palmas y árboles con frutos carnosos (Wainwright 2007). Además, se sabe que puede comer flores e insectos (Mora, 1984). Poco se conoce sobre su consumo de vertebrados, aparte de la observación de Smythe (1978) de un individuo en cautiverio depredando un ratón, Liomys pictus. Skutch (1995) por su parte señala a la guatusa como una potencial amenaza para el ave hormiguera Myrmeciza exsul, indicando que el mamífero podría dañar los nidos para alimentarse de huevos o pichones. Aparentemente, la información disponible sobre este tópico se limita a relatos anecdóticos o registros no publicados (Acosta-Chaves observ. person.). Por ende, en este manuscrito describimos una de estas interacciones de depredación en condiciones silvestres.

El 05 de junio de 2016 (08h00), observamos un evento de depredación de este roedor sobre un ave canora en el Jardín Botánico Wilson de la Estación Biológica Las Cruces en San Vito, Provincia de Puntarenas, Costa Rica (8.785, -82.95916;1200 msnm). Inicialmente un macho de D. punctata se alimentaba de frutos y raíces, pero repentinamente tras desplazarse sigilosamente se abalanzó sobre un pichón de yigüirro o mirlo pardo (Turdus grayi). Tras capturarlo con sus patas delanteras, el roedor lo mató con sus dientes incisivos, y posteriormente se desplazó algunos metros hasta empezar a consumirlo (Figura 1). La posición que usó la Guatusa para depredar y posteriormente consumir el ave es la misma que usa para alimentarse de semillas; sentándose en sus patas traseras y manipulando el alimento con las delanteras (Mora \& Moreira 1984). Tras unos 15 minutos el roedor había consumido parte del ave incluyendo músculos, vísceras e incluso su cabeza. Finalmente, el roedor huyó sin dejar restos de la presa en el sitio al llevarse parte de la carcasa en el hocico (Figura 1).

La presente observación resulta relevante dado que, tras una exhaustiva revisión bibliográfica, detectamos que el comportamiento depredatorio descrito no se incluye como parte de la historia natural clásica de D. punctata (Smythe 1978, Nowak 1999) o especies relacionadas. Creemos que este evento de depredación evidenciado responde a una conducta oportunista de la especie al aprovechar recursos alimenticios disponibles. Por ejemplo, Smythe (1978) reporta que D. puntacta sigue a tropas de monos para consumir los frutos que dejan caer. Sin embargo, la carne de ave sería un recurso complejo de conseguir para estos animales, dados sus hábitos terrestres y especialmente herbívoros, pero representaría una buena fuente de proteínas y grasas, pues se sabe que en cautividad las consumen (Smythe 1978). Un ave pequeña sería un recurso alimenticio inesperado pero valioso para este mamífero, pues durante el año suele haber escasez de frutos y semillas en el suelo, viéndose incluso obligados a enterrarlas y guardarlas para su posterior consumo (Smythe 1978).

Mammalogy Notes | Notas Mastozoológicas

Sociedad Colombiana de Mastozoología

Vol. 4 Num. 2| 2018 
